\title{
SITUAÇÕES VIVENCIADAS PELOS ALUNOS DE ENFERMAGEM, DURANTE O CURSO, NO CONTEXTO UNIVERSITÁRIO, APONTADAS COMO NORTEADORAS DE CRISES.*
}

\author{
Maria Salete Bessa Jorge**
}

JORGE, M.S.B. Situações vivenciadas pelos alunos de enfermagem, durante do curso, no contexto universitário; apontadas como norteadoras de crises. Rev.Esc.Enf.USP. v.30 , n. 1, p. 138-48, abr. 1996.

O estudo aborda as situaçōes vivenciadas pelos alunos dos vários semestres de Enfermagem no contexto universitário que, muitas vezes, podem propiciar sentimentos negativos nos alunos, as quais são apontadas como crises, bem como as ações desenvolvidas no enfrentamento das dificuldades. O método de coleta baseouse em questões abertas para que os mesmos respondessem livremente. $A$ análise dos depoimentos foi realizada categorizando-os em forma de temáticas. O estudo mostrou as dificuldades dos alunos relacionadas consigo próprio, com os colegas, de ordem estrutural e financeira, entre outras.

UNITERMOS: Estudantes de Enfermagem. Estudantes universitários. Crises. Dificuldades.

\section{APRESENTAÇÃO}

O principal objetivo desta pesquisa é conhecer as dificuldades dos estudantes de enfermagem no processo de ser aluno universitário. Percebese que a entrada brusca desses alunos, num contexto ainda desconhecido, contribui para o surgimento de tensões e ansiedades. Além de vivenciarem um mundo desconhecido durante o processo de formação, eles poderão sofrer desgastes de natureza emocional que ressurgem no momento em que aparecem, sob sua ótica, as situações pois são avaliadas e interpretadas pelos alunos de enfermagem, tendo como base as suas experiências passadas.

* Trabalho apresentado no $46^{\circ}$ Congresso Brasileiro de Enfermagem. Porto Alegre-RS. 1994.

** Enfermeira. Professora da Universidade Estadual do Ceará. Aluna do Doutorado Interunidades da Escola de Enfermagem de Ribeirão Preto-USP e Escola de Enfermagem da Universidade de São Paulo 
Outros fatores podem também contribuir para aumentar os sentimentos negativos dos alunos, dentre eles a preocupação com o mercado de trabalho. Esses fatores são apontados em outro trabalho realizado por SILVA (1994), com alunos que estão cursando o $8^{\circ}$ semestre do Curso de Enfermagem, tais como os de natureza econômica, financeira, relacionamento com professores, e outros.

Com o vivenciar dessas situações, os alunos passam por momentos de dificuldades que são trabalhadas por eles de acordo com as suas experiências anteriores, a sua concepção da situação, a sua personalidade, podendo avaliar, reavaliar e encontrar mecanismos que possam ajustar-se ou adaptar-se à nova situação ou poderá confirmar-se a crise. Crises essas denominadas por RODRIGUES (1986) como existenciais ${ }^{2}$ ou acidentais ${ }^{3}$. Estas crises acidentais são difíceis de prever. Dentre as situações que têm desencadeado crises acidentais podem ser citadas as mudanças para um novo ambiente, novas responsabilidades sociais e ocupacionais, nascimento de um bebê prematuro, desemprego, doença, problemas interpessoais, conflitos entre o lar e trabalhos, entre outros.

Observa-se que as pessoas têm uma tendência natural em manter seu equilíbrio. Assim, a personalidade vai amadurecendo gradativamente com o passar dos anos, sob a influência de fatores psicossociais, numa intrínseca relação com a sociedade; ao fazer frente aos impasses que se lhes apresentam, a pessoa reage tentando manter seu equilíbrio. As mudanças que vão ocorrendo conduzem a uma maior maturidade e fortalecem o self e, conseqüentemente maiores níveis de saúde.

Dessa forma, destaca-se tambem que os estudantes de enfermagem ao iniciar o curso enfrentam a sensação de independência, pois saem de casa e têm que administrar seu dia-a-dia ou mesmo as atividades e o convívio com colegas independentes estimulam cobranças, muitas vezes reavaliando sua opção profissional, o que fazem constantemente reafirmando sua escolha ou criando sérias dúvidas a esse respeito (RODRIGUES et al, s.d.).

Percebe-se que num processo educacional reflexivo, todas as etapas evolutivas da experiência dos indivíduos são sujeitas às modificações em sua estrutura de pensar e agir, que, para LAGANÁ (1989), ao proporcionar às pessoas a oportunidade de discutirem sobre sua atividade de vida diária ou de trabalho, elas são capazes de refletir sobre suas experiências e buscar a dimensão de sua própria vida em sua prática de trabalho; de passar as significações de experiências para contextos mais gerais como o social e o econômico; de tomar consciência das relações sociais de dominação extrapoladas por todos os segmentos do seu mundo vida.

Assim, essas pessoas sentem-se mais capazes de serem o que são, tomando consciência de sua própria condição humana e social como ser-nomundo e adquirindo forças para superar as dificuldades frente ao mundo, motivadas pela compreensão da situação vivenciada. 
Para HEIDEC YGER (1981), relacionar-se de uma maneira envolvente $\mathbf{e}$ significativa com pessoas implica em levar em consideração o outro. Significa possibilitar ao outro assumir seus próprios caminhos, amadurecer e encontrarse consigo mesmo.

Reportando-se às dificuldades dos estudantes no meio universitário, verifica-se que existem poucos trabalhos que abordam o aluno no processo de adaptação ao contexto universitário, quais os mecanismos que utilizam para enfrentar esse processo e quais as dificuldades encontradas, a fim de superálas. Essa afirmação é corroborada conforme levantamento bibliográfico no momento da realização da dissertação de mestrado de (JORGE,1992).

O estudo sobre "o aluno ingressante na universidade - uma perspectiva de compreensão" por mim realizado durante o mestrado em 1992, também mostrou uma acentuada preocupação dos alunos com a responsabilidade assumida, pois esses alunos têm que caminhar com seus próprios pés, para serem seres independentes, tornando-se adultos. Nessa perspectiva, percebese que tanto o desenvolvimento biologico quanto o social promovem grandes mudanças qualitativas e quantitativas na pessoa que os atingem e sensibilizam o psiquico, principalmente quando têm que superar os obstáculos. Os alunos vivenciavam sentimentos de realização, pelo fato de terem ingressado na universidade e transposto a barreira do vestibular como um grande passo na vida e trazem aindaconsigo o reflexo de uma luta travada tão recentemente, visto que oles estão ingressando em um mundo ainda desconhecido e que o vestibular representa hoje a adaptação ou o fracasso do indivíduo, condicionando muitos de seus comportamentos futuros e influindo no desenvolvimento da auto-estima.

Pelo levantamento realizado junto aos Cursos de Enfermagem no Brasil por JORGE e RODRIGUES (1994), sobre os serviços de apoio ao estudante de enfermagem, verificou-se que existem duas formas de assistílos: a que oferece informações pedagógico-administrativas e a que oferece algum tipo de atendimento voltado para as necessidades do estudante. Dentre os cursos que oferecem informações pedagógico-administrativas, extraímos de suas respostas a exata colocação da atividade desenvolvida, tais como: Semana de orientação, atendimento das dificuldades do processo de aprendizagem, orientação para bolsa de estudo, entre outros.

Como se pode verificar, parece que esses cursos não demonstram preocupação com o aluno como pessoa que vivencia uma situação de dificuldade, quer na esfera física. psíquica ou sócio-econômica. Interpretouse dessa forma, visto que, oferecendo informaçoes sobre a estrutura do curso, a distribuição de disciplinas, ou recursos administrativos, etc., o aluno fica orientado quanto aos aspectos formais o que é feito de maneira geral e impessoal. O outro grupo de respostas identificadas, demonstra preocupação com seus alunos, oferecendo orientação acadêmica, encaminhamento para outros servicos da comunidade quando necessario, atendimento 
individualizado durante todo o curso segundo o modelo de Travalbee e atendimento grupal segundo o modelo de Pichón Riviéri, entre outros (JORGE; RODRIGUES, 1994).

D'ANDREA e ALMEIDA (1988) colocam que a incidência de crise entre estudantes de medicina ê elevada e um dos grupos de risco em maior evidência é o dos jovens universitários susceptíveis à crises por causa da morosidade psicossocial a que estão sujeitos: maduros biologicamente para serem socialmente adultos, têm, na verdade, "status" de adolescentes, desde que estão vivenciando um longo ritual de iniciação antes de serem liberados para os papéis a que estão destinados. Ainda, neste estudo, os autores referem que, entre os fatores apontados como predisponentes de crises, os alunos citaram a falta de orientação e apoio dos professores, ensino deficiente e totalitário, relacionamento difícil com colegas, dificuldade na integração das diferentes disciplinas do currículo, falta de visão à aplicação dos conhecimentos adquiridos.

Percebe-se que essas dificuldades mencionadas pelos alunos de medicina também são vivenciadas por estudantes de outros cursos da área de Saúde e de Ciências Sociais, conforme pesquisa realizada por (JORGE, 1990,1992)

Dessa forma, e importante observarmos qual a interpretação dada pelo aluno para a experiência no contex to universitário definida por ele como crise.

CAPLAN (1980) considera a crise como o desequilíbrio entre a dificuldade e a importância do problema e os recursos de que a pessoa dispõe, no momento, para enfrentála, pois poderá ser temporária. A resolução de uma crise depende do reajuste de um complexo de forcas conflitivas durante o periodo de desequilíbrio, algumas das quais se originam no interior do indivíduo, estando relacionadas com a estrutura da personalidade e com a experiência biopsicológica passada. Outras surgem do seu ambiente, em particular da evolução das dificuldades externas (situações enfrentadas) e de ajuda ou interferência prejudicial de terceiros (familiares e amigos, etc.).

BARRETO (1993) destaca que a crise "parece ser uma companheira inseparável da convivência humana e, no entanto, muitos ainda não conseguiram fazer dela a força motriz das transformações sociais". Além disso, o autor a define como uma exaustão de um modelo de relacionamento, seja ele afetivo, político, econômico, religioso, que não mais corresponde às exigências de uma realidade, pois a realidade é dinâmica e exige adaptações e mudanças constantes.

Neste sentido, pelo que apreende-se da abordagem de BARRETO (1993) as dificuldades emocionais exacerbadas dos estudantes universitários em seu cotidiano poderão até ser uma forma de assinalar que a maneira de se relacionar não é adequada, configurando-se como uma alerta para que procurem repensar as diversas relações com o meio ambiente que os circunda.

Nessa perspectiva, é importante que a universidade crie um espaço 
para que os estudantes possam reativar sua energia positiva e os professores, principalmente, possam efetivamente contribuir com a saúde mental desses alunos no momento de suas dificuldades.

Frente às situações apontadas pelos autores e pelos alunos universitários, este estudo tem como objetivos:

Identificar as dificuldades presentes nos estudantes de enfermagem que contribuem para o processo gerador da situação de crise;

Identificar as ações dos alunos no enfrentamento das situações consideradas por eles, como dificuldades no mundo universitário.

\section{METODOLOGIA}

Estudo de natureza descritiva, qualitativa, em que procuramos identificar nos depoimentos dos alunos de enfermagem os significados, as intencionalidades, as dificuldades e as ações desenvolvidas por eles ao vivenciar o mundo universitário. Portianto, buscamos conhecer as dificuldades apontadas por eles como desencadeadoras de situações difíceis e os mecanismos enfrentados para superá-las.

O estudo realizou-se em uma instituição universitária de FortalezaCeará, com alunos de enfermagem matriculados nos semestres, $2^{\circ}, 4^{\circ}, 5^{\circ}$ e $8^{\circ}$ do respectivo curso.

A seleção dos participantes da pesquisa deveu-se à necessidade de conhecer esse grupo, primeiramente, para, posteriormente, realizar-se esse mesmo estudo com estudantes de outros cursos que não sejam da área de saúde, a fim de responder ao questionamento: será que os estudantes das ciências exatas e humanas passam também por esse processo no mundo universitário?

Os sujeitos que participaram da investigação foram em número de seis

A coleta de dados foi conduzida atraves de um roteiro com perguntas abertas, as quais foram respondidas descritivamente, como seguem:

Como você vivencia as situações no contexto universitário?

Que ações você desenvolve em função das situações consideradas dificeis?

O processo de vivenciar o contexto universitário favorece o desenvolvimento de dificuldades?

Como método de análise foram utilizados os fundamentos da pesquisa qualitativa (TRIVIÑNOS, 1987). levando em consideração as respostas dos alunos participantes da pesquisa. 


\section{CONSTRUÇÃO DOS RESULTADOS}

Como recurso de análise, utilizamos os princípios da pesquisa qualitativa, tais como: leitura dos depoimentos para obter a compreensão do todo; a seguir, relemos várias vezes esses depoimentos com o objetivo de focalizar as dificuldades e as ações desenvolvidas por eles, no enfrentamento das situações vivenciadas pelos sujeitos da pesquisa no decorrer de sua formação profissional e, a seguir construímos as temáticas, que serão apresentadas e ilustradas com suas falas.

\section{Dificuldades apontadas pelos estudantes de enfermagem enfrentadas no contexto universitário.}

Os alunos revelaram. em seus depoimentos, dificuldades no relacionamento com professores, ensino deficiente (o que poderá gerar dificuldades no exercício da profissão), problemas de natureza econômica, financeira e conflitos de natureza interna. Pode-se destacar que essas dificuldades podem at ć desencadear fortes emoções, as quais deixam os alunos instáveis para atingir seus objetivos, dificultando, assim, a aprendizagem.

Para IDE et al (1985), os enfermeiros que pesquisam recebem, em parte, subsídios suficientes, que podem contribuir para diminuir o descompasso entre teoria e prática. Isto, parece ocorrer pelo despreparo do docente e campo de estágio deficiente com experiências limitadas.

Essas situaçōes vivenciadas pelos alunos, no contexto universitário, precisam ser olhadas com mais atenção por aqueles que fazem a universidade, principalmente os docentes que estão mais próximos da realidade do aluno. A assistência emocional ao estudante é relevante durante a formação do enfermeiro, pois poderá atenuar ansiedades, conflitos e preocupações e, assim, contribuir para o seu crescimento como pessoa, por favorecer o alcance da maturidade ou atuar como episódio causador de dificuldades inerentes ao indivíduo, diminuindo, assim, a capacidade de lidar com a situação vivenciada. Nesse sentido, VISC(OTT (1982) aponta que existem duas espécies de sentimentos: os negativos e os positivos. Os sentimentos positivos ampliam nosso senso de força e bem-estar, produzindo prazer, uma sensação de inteireza, vida, plenitude e esperança, enquanto que os sentimentos negativos interferem no prazer, consomem energia e nos deixam com sensação de truncamento, vazio e solidão.

Destarte, percebe-se que pela própria natureza humana, as dificuldades acompanham o indivíduo por toda sua existência, não convivendo constantemente com a pessoa, mas temporariamente, pois esses danos emocionais, de vez em quando, são importantes para o seu desenvolvimento. Pode até a pessoa sentir-se exaurida de energia. e ferida e desesperançada durante algum tempo. mas isso e natural pois, reflete uma perda. 
VISCOTT (1982) aponta que esse processo de resolver problemas emocionais ao longo da vida torna possível um real crescimento e desenvolvimento. Dessa forma, os aspectos desenvolvimentistas da infância reaparecem constantemente como conflitos em nossas vidas e continuam a nos modelar. Se permanecermos abertos, isto e, exteriorizando nossos pensamentos e sentimentos, poderemos continuar a crescer e, se nos fecharmos em nosso próprio mundo, perderemos a oportunidade de recompor a energia e nunca realizar nosso potencial. Portanto, os sentimentos devem refletir o presente e propiciar uma perspectiva pessoal sobre os eventos com os quais se defrontam, procurando ficar livres da necessidade de distorcer a realidade, a fim de evocar sentimentos do passado, para examiná-los, reavaliálos e definílos de outra forma, isto é, levando em consideração o passado, o presente e o futuro.

Os alunos mostraram essas dificuldades através desses depoimentos:

"Acho que lodos aqui são individualistas, a concorrência faz com que isso aconleça..." (A. $1^{4}, 5^{\circ}$ semestre)

“...o mesmo é muitas vezes discriminado... o aluno calado que não faz perguntas é considerado bom aluno $e$ o que pergunta, discute, é visto discriminado... existem situações vividas que me deixam chaleada... se as autoridades compelenles pudessem melhorar a situasão de nós alunos $e$ dos docentes melhorando a qualidade do ensino..." (A.2, $4^{\circ}$ semestre)

“...Enfrenlamos diversos problemas referentes a professores não capacilados, falta de livros nas bibliotecas, falta de prálica..." (A.4, $5^{\circ}$ semestre)

"Uma siluação de expectativa e medo, por me sentir ainda muito imalura para assumir a profissão; dificuldades financeiras para conchuir esle curso..." (A.5, $8^{\circ}$ semestre)

"Existem muitas dificuldades, não há incentivo da instiluicão para com o crescimento do aluno... dificuldades financeiras e a responsabilidade enorme de cumprir meus papéis e relribuir à sociedade com os serviços profissionais... é uma problema vivenciado pelos universilários e é molivo de stress." (A.6, 8"s somestre)

"Eu já passei por várias dificuldades aqui... com trabalhos de pesquisa, relacionamento com professores e com colegas de curso. O aluno é visto na universidade como um perigo quando quesliona, reclama seus direitos... é discriminado." ( $\Lambda .5,8^{\circ}$ semestre) 


\section{Ações desenvolvidas pelos alunos de enfermagem ao vivenciar situações difíceis no contexto universitário.}

Os alunos mostraram em seus depoimentos vários mecanismos no enfrentamento das situações ou para superar as dificuldades no contexto universitário, entre eles: isolando-se, dividindo com os colegas suas inquietações, esperando uma retribuição futura, buscando embasamento teórico fora da universidade e através de outros colegas que vivenciaram a mesma situação. Mostram sentimentos de esperança, confiança em si mesmos, e em uma força conjunta, como forma de superar as dificuldades da vida diária.

Percebe-se que esses alunos denotaram medo, ansiedade e uma certa preocupação por não se sentirem preparados para enfrentar a realidade lá fora e colocam essa culpa somente na instituição e no corpo docente, esquecendo-se que eles fazem parte do processo ensino-aprendizagem, e que as políticas educacionais também favorecem esse ensino de má qualidade. Toda educação foi direcionada para aceitação de uma certa passividade, acomodação, acriticidade, o que impede de romper esses vícios, impossibilitando dar um salto de qualidade que a coloque como a mentora da abertura dos caminhos para a solução ou atendimento dos anseios das principais questões que envolvem a sociedade moderna. O que estão fazendo para superar as dificuldades de aprendizagem, deixadas pelos responsáveis pela produção do conhecimento, transmissão e utilização adequada desses conhecimentos? Essa preocupação é salutar mas é necessário que percebam que essa lacuna pode ser preenchida com mecanismos que dependem também do aluno, que precisa conscientizar-se que faz parte desse processo e que cabe a ele uma parcela da responsabilidade desse aprendizado e, para isso, torna-se necessário que realize ou tras atividades extracurriculares, tais como: diálogo com os docentes de uma forma madura, procurando esclarecer suas dificuldades e solicitar reforço; estudos individualizados e grupais; participação de pesquisas, entre outros.

VISCOT'T (1982) coloca: "Se você aprendeu a compreender seus sentimentos e a ser aberto e honesto no expressá-los, poderá ficar livre das dúvidas emocionais de seu passado e clarear cada vez mais sua percepção do mundo. Uma vez livre da necessidade de deturpar e das perspectivas preconceituosas solbre a realidade, a vida se tornará menos complicada, tornando-se mais plena. Dessa forma, você mergulha dentro de si mesmo, no real conhecimento de si mesmo."

Segue-se algumas respostas que evidenciam essas ações:

"...se deve procurar tirar lições da vida, as experiências que marcam ou que nos fazem repensar os nossos valores." (A.5, $8^{\circ}$ semestre) 
"Procuro pensar que, apesar das dificuldades, mais tarde haverá retribuição salisfatória ou não..." (A. 6, $8^{\circ}$ semestre)

"Não posso enfrentar o mundo sozinho... para alcançar alguma meta se faz necessária a participação de todos." (A.2, $4^{\circ}$ semestre)

"...os alunos devem se conscientizar de seus direitos e deveres para que busquem a experiência e o conhecimento..." (A.3, 2 ${ }^{\circ}$ semestre)

"...ficar calada ou buscar ajuda com professores fora da universidade e muita força de vontade." (A.4, $5^{\circ}$ semestre)

\section{CONSIDERAÇÕES FINAIS}

Este estudo se propôs a investigar as situações vivenciadas pelos alunos de enfermagem no decorrer de sua formação profissional no contexto universitário.

Pelos depoimentos dos estudantes, observou-se intensa preocupação em assumir seu papel no mercado de trabalho, alem de sentimentos de apreensão, ansiedade e fragilidade referentes aos aspectos estruturais, ideológicos da universidade e à deficiência do ensino.

Demonstraram uma certa preocupação em retribuir à sociedade com os serviços profissionais, mas acham-se incapacitados para assumir esse papel. Isso nos leva a refletir que alguns dos alunos estão com o senso crítico mais aguçado e têm uma visão de cidadania, pois em seus depoimentos surgem frases em que estão presentes esses valores:

"...os alunos devem se conscientizar de seus direitos e deveres, para que busquem experiência e o conhecimento..." (A.3, $2^{\circ}$ semestre);

"Não posso enfrentar o mundo sozinho... para alguma meta se faz necessária a participação de todos." (A.2, $4^{\circ}$ semestre)

Percebe-se que os alunos têm uma expectativa muito forte quanto à formação profissional, colocando todo o seu fracasso na instituição e nos professores, como se o aluno fosse um mero receptor de conhecimentos e não tivesse participação ativa no processo.

Apontaram como alternativas ou ações para superar as dificuldades, o isolamento, a luta com a participação dos colegas, buscando embasamento teórico sólido e a busca de conhecimento prático com colegas que já 
vivenciaram situações semelhantes, utilizando as experiências para repensar os valores e, finalmente, esse enfrentamento é manifestado através da luta e da conscientização de seus direitos e deveres.

Observa-se que dos seis alunos pesquisados, somente um aluno apontou os problemas financeiros, econômicos e sociais como dificuldades no desenvolvimento de suas ações no mundo universitário, inclusive necessitando ajuda de colegas para ter condições de continuar:

\section{"Passei por diversos problemas financeiros no decorrer do curso..." (A.6, $8^{\circ}$ semestre)}

Os problemas mais apontados pelos alunos como desencadeadores de dificuldades foram os de natureza profissional relacionados ao ensino, ao papel que a universidade deve desempenhar na formação do aluno, e os de ordem emocinal emergidos no enfrentamento das situações vivenciadas.

JORGE, M.S.B. Situations lived by the nursing students during the course in the university context appointed as a leader of crises. Rev. Esc. Enf. USP. v.30, n. 1, p.138-48, Apr. 1996.

The study approaches the situations lived by the students of the various semesters of nursing in that University context, that, can often render negative feelings to the students, which are appointed as crisis and the actions developed in coping with difficulties. The method of collect was based answer on questions openned in order that the same ones could answer freely. The analysis of the testimonies carried in a classifying form thematic. The study showed the difficulties of the students concerning themselves, with the collegues, of structural and financial order, etc.

UNITERMS: Students of Nursing, Crisis, Students University, Difficulty

\section{REFERÊNCIAS BIBLIOGRÁFICAS}

BARRETO, A.P. Como administrar crises e conflitos na comunidade. Jornal o Povo., n.6, p.3, 1993.

CAPLAN, G. Princípios de psiquiatria preventiva. Rio de Janeiro, Zahar, 1980.

D'ANDREA, F.F.; ALMEIDA, O.M.L. Crise em estudantes de medicina. J. Bras. Psiq., v.6, n. 37, p.313-15, 1988 .

HEIDEGGER, M. Todos nós... ninguém: um enfoque fenomenológico do social., São Paulo, Morais, 1981.

IDE, C.A.C. et al. O seguimento do graduando em enfermagem. Rev. Esc. Enf. USP, v.19, n.3, p.195-211, 1985. 
JORGE, M.S.B. Oaluno ingressante na universidade: uma perspectiva de compreensão.

Ribeirão Preto, 1992. 84p. Dissertação (Mestrado) - Escola de Enfermagem de Ribeirão Preto, Universidade de São Paulo.

Dificuldades dos estudantes de enfermagem psiquiátrica durante a prática da disciplina, ao lidar com o doente mental. Traballo apresentado no $42^{\circ}$ Congresso Brasileiro de Enfermagem. Natal. RN. 1990

JORGE, M.S.B.; RODRIGUES. A.R.F. Ajuda de enfermagem a aluno ingressante na graduação. In: SIMPÓSIO BRASILEIRO DE ENFERMAGEM. 3. Ribeirao Preto. Anais. Ribeirão Preto, 1992,p. 152-65.

JORGE, M.S.B.; RODRIGUES. A.R.F. Serviços de apoio ao estudante oferecidos pelas Escolas de Enfermagem do Brasil. Rev. Lat Amb. Enf., 1994 (No prelo)

LAGANÁ, M.T.C. A educação para saúde: o cliente como sujeito da ação. Rev. Esc. Enf. USP, v.23, n.1, p.149-61. 1989.

RODRIGUES, A.R.F. Enfermagem em saúde mental para mulheres em crise acidental Ribeiráo Preto, 1986, 129p. Tese (Doutorado) - Escola de Enfermagem de Ribeirão Preto, Universidade de Sāo Paulo.

RODRIGUES, A.R.F. et al O aluno ingressante na enfermagem: abordagem compreensiva. Rev. Gaúcha Enf. (No prelo)

SILVA, C.F. Sentimentos, expectativas e preocupações dos graduandos de Enfermagem em relaçáo ao exercício de sula futura prática profissional: análise comparativa entre duas instituiçoes de ensino. Fortaleza. Universidade Estadual do Ceará, 1994.

TRIVIÑOS, A.N.S. Introduçào à pesquisa em ciências sociais: a pesquisa qualitativa em educação. São Paulo. Atlas. 1987. p.116-73: Pesquisa qualitativa.

VISCOTT, D. A linguagem dos sentimentos. São Paulo, Summus, 1982. 